ISSN 1518-3483

Licenciado sob uma Licença Creative Commons

(c) (1)

\title{
Linguagem, dialogicidade e docência: o processo de formação em atos
}

\author{
The language and dialogical exchange in the process of \\ teacher training
}

El Lenguaje, interacción y dialogicidad en el processo de formación docente

\section{Ilsa do Carmo Vieira Goulart*}

Universidade Federal de Lavas (UFLA), Lavas, MG, Brasil

\section{Resumo}

Este texto parte da premissa de que a proposta de um trabalho formativo acontece subsidiado por reflexões da prática pedagógica, movidas tanto a partir do domínio teórico do conhecimento e saberes acumulados sobre a educação, quanto da capacidade de saber mobilizá-los em situações concretas de articulação da linguagem

* ICVG: Doutora em Educação, e-mail: ilsa.goulart@ded.ufla.br 
num processo de relação interpessoal. $O$ ato de refletir sobre a prática, pode ser compreendido como um movimento de articulação ativa e interativa da capacidade discursiva, por envolver atos de se rever, repensar, reorganizar e retomar o vivido ou experienciado, o que se mostra um trabalho constante de ir e vir de um processo de construção, reconstrução ou desconstrução de um diálogo interior. Nesta perspectiva, este trabalho assume por objetivo refletir sobre a linguagem como interação verbal e dialogicidade no processo de formação docente e compreender como a articulação desta linguagem pode contribuir na construção da identidade do professor. Para isso, propõe-se a realização de uma pesquisa bibliográfica, que discorrerá a respeito da linguagem na abordagem dialógica de Bakhtin, com a Teoria da Enunciação e na concepção teórica da dialogicidade de Paulo Freire, com a Pedagogia da Humanização. Neste sentido, o trabalho procurará compreender e sinalizar aproximações entre as duas proposições teóricas, bem como a articulação e caracterização no processo de formação de educadores.

Palavras-chave: Linguagem. Interdiscursividade. Dialogicidade. Formação docente.

\section{Abstract}

This text is part of the premise that the proposal of a formative work happens subsidized by reflections of pedagogical practice, moved both from the theoretical domain of knowledge and knowledge accumulated about education, as the ability to know mobilize them in concrete situations of articulation of language in a process of interpersonal relationship. The act of reflecting on practice, can be understood as a movement of active and interactive joint discursive capacity, a stock surge to review, rethink, reorganize and resume lived or experienced, which shows a steady work to go and come from a process of construction, reconstruction or deconstruction of an interior dialogue. In this perspective, this work takes aim to reflect on language as verbal interaction and exchange in the process of teacher training and understand how the articulation of this language can contribute to the construction of the identity of the teacher. For this, it is proposed to carry out a literature search, which speaks about the language in the dialogical approach of Bakhtin, Enunciation Theory and theoretical Exchange design of Paulo Freire, with the Pedagogy of Humanization. In this sense, the work will seek 
to understand and flag approaches between the two theoretical propositions, as well as the joint and characterization in the teacher training process.

Keywords: Language. Interdiscursivity. Exchange. Teacher training.

\section{Resumen}

Este texto parte de la premisa de que la propuesta de un trabajo formativo acontece subsidiado por reflexiones de la práctica pedagógica, movidas tanto a partir del domínio teórico del conocimiento y saberes acumulados sobre la educación, cuanto de la capacidad de saber mobilizarlos en situaciones concretas de articulación de la lenguaje en el proceso de relación interpersonal. El acto de refleccionar sobre la práctica, puede ser comprendido como un movimiento de articulación activa e interactiva de la capacidad discursiva, en una osilación de acciones de se rever, repensar, reorganizar y retomar lo vivido, lo experimentado, lo que se muestra un trabajo constante de ir y de venir de un proceso de construción, reconstrución y desconstrución de un diálogo interior. En esta perspectiva, este trabajo asume por objectivo refleccionar sobre el lenguaje como interación verbal y dialogicidad en el proceso de la formación docente y comprender como la articulación de esta lenguaje puede contribuir en la construción de la identidad del profesor. Para eso, se propone la realización de una pesquisa bibliográfica, que discorrerá a respecto del lenguaje en la abordaje dialógica de Bakhtin, con la Teoria de la Enunciación y en la concepción teórica de la dialogicidade de Paulo Freire, con la Pedagogia Humanizadora. En este sentido, el trabajo procurará comprender y sinalizar aproximaciones entre las dos proposiciones teóricas, bien como la articulación y caracterización en el proceso de la formación de educadores.

Palabras clave: Lenguaje. Interdiscursividad. Dialocididad. Formación del professorado.

Jamais atingimos um estado em o homem estivesse separado da linguagem, que elaboraria então para exprimir o que nele se passasse: é a linguagem que ensina a definição de homem, não o contrário. Barthes (2004, p. 15) 


\section{Introdução ${ }^{1}$}

Com a expansão dos recursos tecnológicos, da mídia eletrônica, do avanço dos meios de telecomunição e da adesão em massa às redes sociais, se observa que o homem utiliza a potencialidade das múltiplas linguagens. Materializada em diferentes suportes, as linguagens híbridas repercutem significativamente nos modos de agir, interagir e compreender as inter-relações sociais, o que impacta diretamente nas formas de relação do sujeito consigo mesmo, com o outro e com o conhecimento. Parafraseando a epígrafe, jamais atingimos um estado em que o homem estivesse tão conectado à uma diversidade da linguagem.

Por trabalhar de forma contundente com as linguagens, a instituição educativa enfrenta inúmeros desafios em sua conjuntura para compreender modos de aproximação deste sujeito com o conhecimento, com vistas a abranger as demandas institucionais e as exigências cognitivas e afetivas dos discentes. Observa-se que as ações pedagógicas se mostram, por vezes, balizadas por diferentes concepções da linguagem no processo de ensino e aprendizagem, o que gera divergências de opiniões, distanciamento entre os profissionais da educação, descontinuidade de propostas pedagógicas, enfim, rompimentos e fechamento de diálogos.

É no movimento interdiscursivo, entre as exigências sociais e os modos de apropriação dos sujeitos, que emerge a necessidade de se criar espaços de discussão e reflexão sobre a dinâmica do cotidiano escolar e sua relação com a realidade social, bem como sobre o papel de atuação e mediação docente entre o sujeito que aprende e o conhecimento, como também entre os sujeitos docentes.

Neste sentido, o processo de formação dos profissionais da educação, especificamente para a docência, requer um ambiente que

1 Este texto trata-se da ampliação do trabalho apresentado no VI Encontro de Estudos da Linguagem e V Encontro Internacional de Estudos da Linguagem - Linguagem, Tecnologia e espaço social, realizado em 2015, pelo Programa de Pós-graduação em Ciências da Linguagem, da UNIVÁs. 
proporcione a reflexibilidade da própria prática pedagógica. Algumas pesquisas dedicaram-se a compreender a complexidade que envolve o processo de formação continuada de professores, como Freire (1987, 1996), Nóvoa (1989, 1995), Mizukami (1996), Candau (1996), Perrenoud (2000), Perrenoud e Thurler (2002), Freitas (2002), Contreras (2002), Tardif (2002), Falsarella (2004), Sousa Neto (2005), Ferreira; Albuquerque e Leal (2007), entre muitos outros.

Este trabalho apoia-se na concepção de Freire (1996) por considerar a formação docente como um processo contínuo e permanente, sinalizando que a docência se constitui a partir da visão do seu inacabamento enquanto ser humano. A condição humana circunda-se da ideia de inconclusibilidade, de certa descontinuidade metódica e sistemática, ou melhor, a formação docente perpassa um processo demarcado não por sequências lógicas, seja em relação ao conhecimento científico, ao conteúdo curricular, seja em relação à operacionalização das ações, à elaboração e desenvolvimento de atividades pedagógicas. A experiência vital, segundo Freire (1996, p. 62) caracteriza-se pela sua incompletude, visto que "[...] onde há vida, há inacabamento".

A formação docente se configura a partir de um movimento contínuo de ação e reflexão, este, que articula atos e atuações num âmbito de aproximações entre a experiência do cotidiano escolar e a concepção teórica. Longe de ser um espaço caracterizado pela neutralidade e indiferença, o fazer docente, ainda que balizado pela premeditação, meticulosidade e metodização imposta institucionalmente, acontece na esfera da complexidade e da amplitude das relações humanas. O que exige a compreensão de que "[...] não posso ser professor se não percebo cada vez melhor que, por não poder ser neutra, minha prática exige de mim uma definição. Uma tomada de posição. Decisão. Ruptura. Exige de mim que escolha entre isto e aquilo" (FREIRE, 1996, p. 63).

Frente a tal perspectiva, este texto entende que a formação docente se trata de um espaço de articulação e reflexão discursiva da realidade, no qual o professor é compreendido como sujeito agente e convergente, entre os alunos e seus pares, desencadeando uma diversidade de saberes e atitudes. 
Ao destacar o processo discursivo, sinaliza-se a palavra como linguagem em movimento articulador de ações, atuações e relações humanas. Deste modo, o texto assume por objetivo refletir sobre a linguagem como processo interativo e dialógico, como também compreender a articulação desta linguagem com a filosofia do ato e sua relação com a construção da identidade do profissional docente.

Considerando a complexidade que envolve as relações humanas e o processo de formação docente, este trabalho procura, com base na concepção de Pedagogia Libertadora de Paulo Freire e na Teoria da Enunciação de Bakhtin, articular uma reflexão temática dividida em três espaços discursivos. No primeiro se discutirá sobre a formação docente na perspectiva do dialogismo e da filosofia do ato. No segundo, as discussões voltam-se para a formação docente na perspectiva Humanística, para em seguida, criar-se um espaço dialógico de aproximação entre as duas perspectivas teóricas.

\section{Formação docente: da perspectiva da filosofia do ato ao dialogismo}

Partindo da premissa de que é a partir do efeito mobilizador das palavras que, segundo Bakhtin (2006, p. 115) "[...] defino-me em relação ao outro", o processo de formação inicial e continuada de educadores, compreende não apenas a face da aquisição de conceitos, mas abrange um aspecto mais alargado e intrincado pela dimensão do ato reflexivo do pensamento.

Ao assumir como caráter dialógico sua relação com o processo de formação docente, entende-se que, de acordo com Balzan (1996, p. 38), "[...] mais do que lugar de aquisição de técnicas e de conhecimentos, a formação de professores é o momento chave da socialização e da configuração profissional", que pode ser compreendido pela articulação da linguagem.

Para Balzan (1996), o processo de formação implica condições de aprendizagens do professor relativas às suas intersecções sociais e culturais com seu meio profissional, tanto em termos normativos quanto interativos. Diante do qual podem ser consideradas em relação ao processo 
adaptativo ao grupo ou área de trabalho a que pertence e às características da instituição escolar que se está vinculado, como nas influências culturais entre o professor e o meio social em que vive. $\mathrm{O}$ autor ressalta, ainda, que as oportunidades de socialização profissional devem ser compreendidas como um dos pontos determinantes da formação continuada dos professores.

Como afirma Candau (1996, p. 150), a formação continuada não pode ser concebida como um processo acumulativo de certificados de cursos, palestras, seminários, etc., restrito a conhecimentos ou técnicas ou que se configuraria como uma formação bancária — conforme já discutida por Freire (1987) — mas sim "[...] como um trabalho de reflexibilidade crítica sobre a prática de (re)construção permanente de u ma identidade pessoal e profissional, em interação mútua".

Neste sentido, pensar o processo de formação docente a partir da perspectiva bakhtiniana da linguagem, parece imprescindível uma cogitação mais acentuada sobre dois pontos teóricos significativos para reflexão temática, como o dialogismo e a filosofia do ato.

Trazer a questão da filosofia do ato em interface com o processo de formação docente, nos coloca em proximidade à compreensão da própria ação reflexiva do sujeito, visto que a ação do pensamento é considerada um ato, porque para Bakhtin (2010, p. 21) "[...] cada pensamento meu, junto com seu conteúdo, é um ato ou ação que realizo - meu próprio ato ou ação individualmente responsável [postupok]”.

Para Amorim (2009), o significado de ato não estaria resumido ao fazer operacionalizado, mas para Bakhtin demanda a compreensão e deve ser caracterizada juntamente à reflexibilidade e à "responsividade", visto que se utiliza do ato de pensar ou de criar. Desta forma, pode-se destacar as atividades de criação teórica ou criação artística como práticas de integrações da cultura. Entretanto, o que Amorim (2009, p. 22) considera importante é a distinção entre ato e ação, de modo que "[...] ação é um comportamento qualquer que pode ser até mecânico ou impensado. O ato é responsável e assinado: o sujeito que pensa um pensamento assume que assim pensa face ao outro, o que quer dizer que ele responde por isso".

Acompreensão entre ato eação, não se trata de uma diferenciação apenas vocabular, mas de implicação atitudinal, pois o ato traz o comprometimento 
do ser, algo pensado e construído, mas uma ação pode ser uma dissimulação, pode corresponder a algo que o sujeito não se responsabiliza.

Deste modo, Amorim (2009, p. 22), também sinaliza que o conteúdo ou o conhecimento sem ato seria um dado abstrato e parcial, ou seja, "[...] para que um conhecimento seja pleno é necessário que alguém o pense. O ato é o movimento do pensamento, é o seu vir-a-ser”.

Outra perspectiva do ato é descrita por Sobral (2008, p. 224), ao apontar que a reflexão sobre o ato se trata de uma reflexão sobre um agir geral o qual envolve os atos particulares, o que requer uma utilização da palavra na pluralidade, visto que "[...] falar de ato é falar ao mesmo tempo de atos. $\mathrm{O}$ ato como conceito é o aspecto geral do agir humano, enquanto os atos são seu aspecto particular, concreto".

De acordo com Sobral (2008, p. 231), pode-se assim dizer que a "concepção dialógica da linguagem" é qualificada como dialógica porque propõe que a linguagem em seu processo discursivo constitui seus sentidos produzidos pela presença constitutiva da intersubjetividade, demarcada pela interatividade verbal e não-verbal, ou seja, nas situações concretas de exercício da linguagem, em forma dos atos linguísticos.

Para Sobral (2008) a intersubjetividade é entendida em termos psíquicos, sociais e históricos, em vez de puramente psicológicos, e é considerada como corolário a condição de possibilidade da subjetividade. Também de caráter psíquico, social e histórico: o sujeito da linguagem, sujeito do discurso, é um agente, ou melhor, um "interagente", alguém que age na presença mediata ou imediata de outro(s) agente(s).

E neste sentido, que para Sobral (2008) o conceito de dialogismo aparece vinculado indissoluvelmente ao de interação, considerado a base do processo de produção dos discursos e, o que é mais importante, da própria linguagem. De acordo com círculo bakthiniano, o locutor e o interlocutor têm o mesmo peso, porque toda enunciação é uma respos$t a$, uma réplica a enunciações passadas e a possíveis enunciações futuras. Ao mesmo tempo uma pergunta, uma interpelação a outras enunciações: o sujeito que fala o faz levando o outro em conta, não como parte passiva, mas como parceiro ativo, seja este colaborativo ou hostilizado. 


\section{Formação docente na perspectiva Humanística}

A formação docente é destaque em alguns documentos oficiais, como se pode observar nas orientações da Resolução n. 4, de 13 de julho de 2010, que define Diretrizes Curriculares Nacionais para a Educação Básica, o processo de formação inicial e continuada dos professores aparece descrito no caput IV, no Art. 57, cuja preocupação aponta que "Entre os princípios definidos para a educação nacional está a valorização do profissional da educação, com a compreensão de que valorizá-lo é valorizar a escola, com qualidade gestorial, educativa, social, cultural, ética, estética, ambiental".

Partindo da valorização profissional percebe-se a proposta pedagógica da educação baseada nas diretrizes do Art. $2^{\circ}$ PNE - 2011/2020, que traz no parágrafo VII, o destaque à “[...] promoção humanística, científica e tecnológica do País". O Plano Nacional de Educação prevê uma "educação humanística", juntamente com o acesso ao conhecimento específicos curriculares e o aprimoramento tecnológico, mas o que se entende por uma "educação humanística"?

Recentemente, o documento Base Nacional Comum Curricular, BNC (2015), apresenta o destaque a quatro grandes áreas da atuação docente na Educação Básica: Linguagens, Matemática, Ciências Naturais e Ciências Humanas.

As Ciências Humanas compreenderiam além das especificidades dos conhecimentos filosóficos, históricos, geográficos, sociológicos e antropológicos, também abarcaria discussões e "[...] explorações afetivas, lúdicas e sociocognitivas que potencializam sentidos, vivências e experiências como saberes sobre a pessoa, o mundo social e a natureza". (BRASIL, 2015, p. 257).

O documento acentua uma necessidade de criar um espaço dialógico para a formação reflexiva dos alunos, sinalizando nos objetivos demarcações de práticas interdiscursivas como "compreender", "problematizar", "desenvolver a consciência crítica”, " realizar experiências", que podem ser percebidas como um indicativo do ato reflexivo sobre vivências e experiências sociais, como também devem articular-se 
[...] em diálogo com outras áreas e seus respectivos componentes, potencializam a formação integral no desenvolvimento do sentido de pertencimento em grupos sociais, nas percepções de tempos, de temporalidades, de espaços e de espacialidades, cultivando nos sujeitos da educação as corresponsabilidades quanto ao acolhimento do outro e ao mútuo reconhecimento (BRASIL, 2015, p. 257).

Ao documento parece se pautar numa nova exigência para a prática educativa, a dialogicidade, o que demanda uma nova postura docente frente às especificidades curriculares. A mudança na prática docente requer uma retomada das ações pedagógicas, de habilidades argumentativas que proporcionam uma integração interdisciplinar. Entretanto, como explorar a capacidade reflexiva discente, quando, muitas vezes, o professor parece sofrer do estado de desabilidade de atos interdiscursivos?

O desencontro discursivo, parece destilado, na concepção da Pedagogia da Humanização de Freire (1987), quando discorre que é próprio do ser humano buscar de respostas às inquietações, porém esta procura o leva sempre a outras novas indagações, como a respeito do mundo, das coisas, das pessoas, de si mesmo, etc.

Neste movimento de busca por compreensão do mundo que nos cerca, define o processo de humanização, mas, por vezes, se esbarra com um movimento inverso: o de desumanização. Freire (1987, p. 30) esclarece que várias ações agem de forma opressora neste processo, como a injustiça, a exploração, a opressão, a violência, a indiferença, a impaciência, o desprezo, a raiva, a falta de diálogo, entre outras, que, segundo o autor, negam a vocação a que fomos chamados: a vocação a ser homem. A desumanização é entendida como a ação de latrocínio da humanidade, ou seja, são as próprias atitudes dos sujeitos que retiram dele a condição de ser humano.

A proposta de uma Pedagogia da Libertação, segundo Paulo Freire (1987, p. 40), consiste na superação daquilo que o oprime, "[...] é a pedagogia dos homens empenhando-se na luta por sua libertação". A "libertação autêntica" é definida pelo autor como "humanização em processo", não é algo que se deposita no outro, acreditando que no outro como um ser vazio do conhecimento, ou das competências necessárias para vencer o que lhe 
oprime, mas ao contrário, trata-se de uma "[...] práxis, que implica a ação e a reflexão dos homens sobre o mundo para transformá-lo".

Partindo da concepção de que o professor é sujeito ativo e atuando do seu processo de formação, Freire (1996) nos mostra que a questão da formação docente ocorre em fluxo contínuo e paralelo à reflexão sobre a prática.

Segundo Freire (1996) a reflexão crítica sobre a prática se torna uma exigência da relação entre teoria e prática pedagógica, sem a qual a teoria pode vir a se tornar apenas um montante de aglutinação de palavras sem significação, isoladas do contexto real, e a prática pode tornar-se uma ação pela ação ou mero ativismo.

Neste sentido, se considera que o processo de formação, a partir de uma proposta reflexiva e discursiva da realidade escolar, consiste em um processo articulador de ações e atuações, que conforme Freitas (2007, p. 22) compreende um movimento "[...] de transformação ou reconstrução da própria experiência profissional e pessoal dos professores na medida em que eles analisam criticamente os pressupostos da sua ação pedagógica”.

Entende-se que a proposta de um trabalho formativo acontece subsidiada por reflexões, segundo Freire (1996) tanto do domínio teórico do conhecimento e saberes acumulados sobre a educação, quanto da capacidade de saber mobilizá-lo em situações concretas, da aplicabilidade. Refletir sobre a prática, pode ser compreendido como um movimento do ato de pensar, de articulação da capacidade de rever, de repensar, de reorganizar, de retomar ações. Significa um trabalho constante de ir e vir, de construção, reconstrução e desconstrução de um processo dialógico, que também abarca indagações a respeito do que significa ou do que envolve o próprio magistério.

Nesta mesma perspectiva, a atitude reflexiva da prática pedagógica é apontada por Pérez Ferra (2013, p. 60) como uma "[...] indagación como actitud", não compreende apenas saberes da prática, mas um questionamento sobre a atividade docente, sobre o posicionamento em torno do que deve ser a função de professor, visto que "[...] ese posicionamiento (pensamiento del profesor), el docente indaga y reflexiona sobre su vida profesional; cuestiona sus conocimientos y la adecuación de los mismos a su actividad profesional situada, iniciando procesos que abordan las incertidumbres de la tarea docente". 
Para Pérez Ferra (2013, p. 60) é a partir do conhecimento da prática que o professor desenvolve sua própria capacidade de aprendizagem, "[...] se forma y ejerce sus funciones de modo situado a través de vivencias que comportan opciones de significado social, histórico, cultural y político, que suponen un posicionamiento ético ante el hecho educativo".

Assim como Freire $(1996,1987)$, as proposições de Pérez Ferra (2013) a respeito da "indagación como actitud", como uma atitude que possibilita aos professores posicionarem-se frente aos possíveis dilemas que poderão surgir no desempenho da função docente, e, também, frente às mudanças constantes no processo educativo, político-social.

Tal processo reflexivo compreende um diálogo consigo mesmo, corresponde a um ato reflexivo, por criar um espaço de interlocução com outras vozes interiores, outras concepções, crenças e modos de compreender a própria prática docente que conosco dialoga, visto que, de acordo com Bakhtin (2006, p. 151) toda atividade mental e reflexiva, caracterizada como "fundo perceptivo", "[...] é mediatizado para ele pelo discurso interior e é por aí que se opera a junção com o discurso apreendido do exterior. A palavra vai à palavra. É no quadro do discurso interior que se efetua a apreensão da enunciação de outrem, sua compreensão e sua apreciação, isto é, a orientação ativa do falante".

O ato de refletir sobre a prática cria diálogos com outras práticas, num movimento em que a palavra converge a outras palavras. Assim, de acordo com Freire (1996, p. 22) aprendizagem, na formação reflexiva, faz-se acompanhar da competência para construir um discurso sobre a prática, como disposição para confrontar os limites do conhecimento da explicação e solução das questões da realidade.

Considerando a formação como ato de reciprocidade, em cumplicidade com Freire (1996, p. 12), a proposta entende que a formação acontece em movimento de troca de experiências e conhecimentos entre docentes e discentes, visto que "[...] quem forma se forma e re-forma ao formar e quem é formado forma-se e forma ao ser formado".

Nesta perspectiva compreende-se que ensinar ou, no caso formar, não se trata de uma ação única de se transferir conhecimentos ou 
conteúdos, mas de uma ação de reciprocidade entre sujeitos, pois de acordo com Freire (1996, p. 12):

[...] não há docência sem discência, as duas se explicam e seus sujeitos, apesar das diferenças que os conotam, não se reduzem à condição de objeto, um do outro. Quem ensina aprende ao ensinar e quem aprende ensina ao aprender. Quem ensina ensina alguma coisa a alguém.

É na troca de saberes, experiências e conhecimentos, viabilizada pela articulação discursiva, que se permite ao professor agir com maior segurança em sua prática pedagógica. Na troca se permite conhecer a diversidade de ações e atuações, limites e desafios que caracterizam a essência da prática, flexibilizando o desempenho do docente, visto que é na "[...] capacidade de aprender, não apenas para nos adaptar mas sobretudo para transformar a realidade, para nela intervir, recriando-a, fala de nossa educabilidade e um nível distinto do nível do adestramento dos outros animais ou do cultivo das plantas" (FREIRE, 1996, p. 41).

A educação é responsável pelo processo de ação humanizadora, que problematiza a realidade, que reflete sobre o que lhe oprime, o que coloca o processo de formação continuada frente ao desafio de propiciar um espaço de reflexão e isso não seria possível acontecer sem o diálogo entre formadores e formandos.

De acordo com Paulo Freire (1987, p. 79), há uma relação intrínseca entre o diálogo e o amor, visto que "[...] não há diálogo, porém, se não há um profundo amor ao mundo e aos homens". Se não amo o mundo, as pessoas, a vida, o meu trabalho, os alunos como estabelecer um diálogo com eles?

De acordo com os estudos de Prado e Tescarolo (2007, p. 10), esta práxis dialógica "encharcada de amor", proposta por Freire, tem como base o amor, a humildade, a compreensibilidade e a crença do ser humano, "[...] sem os quais seria estéril, verborreia, alienado e alienante".

Os autores destacam que seria a presença desses elementos que faria da práxis pedagógica uma ação mais consolidada, indivisível em sua natureza teórica e prática, tendo em vista que “[...] o diálogo é a palavra 
compartilhada, cheia de sentido, de vida, de experiência que emana da realidade concreta do ser humano".

A fundamentação numa relação "amorizada", cria-se uma relação horizontal, em que prevalece o diálogo, reciprocidade e a confiança. A educação autêntica não acontece do educador para o educando, nem do educador sobre o educando, mas do educador com o educando, mediado pelo mundo social. Desta forma tem-se o diálogo na educação como uma prática libertadora.

A necessidade de formação nos arrebata ao aprimoramento das ações educativas, impulsiona a escolha para além de nós mesmos, para além dos limites da fadiga, das vontades e desejos, abrindo um espaço para se trabalhar dois elementos no eixo de nossa formação: a administração do tempo e a compreensão do nosso processo de aprendizagem.

A formação continuada abre espaço para um ensinamento que ultrapassa o domínio de conhecimentos dispostos na estrutura curricular do curso, e nos coloca em contato com uma dimensão da formação demarcada por um processo determinado pelo sentimento que configura as relações interpessoais, como descreve Adélia Prado (1993, p. 116), no poema Ensinamento, "[...] a coisa mais fina do mundo é o sentimento [...] não falou em amor, esta palavra de luxo", ou seja, compreende a capacidade de se relacionar com o outro e consigo mesmo, a interatividade e a interdiscursividade.

\section{Do processo interdiscursivo ao humanístico: em fios de aproximação}

Considerando que o processo interdiscursivo se trata de um movimento de interação e interlocução entre o sujeito e seus interlocutores ou consigo mesmo, o diálogo interior e o processo humanístico podem ser entendidos como a ativação da essência humana que constitui os sujeitos, tida como fundamento da formação humana ou o processo de composição do próprio ser. 
O ato dialógico sobre o fazer pedagógico redefine-se numa atitude indagadora da própria prática, que se mostra delineado por outros atos. Por isso, pode-se destacar que a filosofia do ato remete ao ato de (re)pensar e (re)criar, e que o percurso da formação docente se constitui a partir da reflexibilidade, visto que, segundo Amorim (2009, p. 22), o ato de pensar é característico de um ser, demarca-se pela singularidade pela capacidade de articular-se com a universalidade, visto que "[...] o sujeito singular que pensa um pensamento participa do ser universal e idêntico completando-o e atualizando-o exatamente com aquilo que não é idêntico nem repetível: o ser real no acontecimento único do ato de pensar".

A atitude indagadora da realidade educacional, no contínuo decurso do que se compreende por docência, se configura em atos e ações dos sujeitos em seu processo formativo, que acontecem em movimentos circulares e em constantes retomadas de posições, os quais integram a dialogicidade como o ato reflexivo, o ato de encantar-se com o fazer pedagógico e o ato de empatia.

\section{$\mathrm{O}$ ato de reflexibilidade da prática}

De acordo com Perrenoud (2000, p. 160) toda prática é reflexiva, em duplicidade, pois o sujeito reflete antes de realizar a ação e posteriormente à atividade executada. Segundo o autor, dedicamos parte de nossa atividade mental a pensar sobre o que foi feito, o que se há para fazer, isto porque "[...] todo ser humano é um prático reflexivo".

Para Perrenoud(2000) a prática reflexiva édefinida como uma atividade de aprendizagem e de auto regulação, pois saber analisar e explicitar a própria prática requer uma capacidade cognitiva de observação dos fatos e de si mesmo, num exercício de lucidez profissional, a partir da conscientização do ato realizado.

Bakhtin (2010, p. 33) apresenta o ato de pensar "[...] na medida em que o ato de cognição esteja incluído como minha ação, com todo seu conteúdo, na unidade da minha responsabilidade, na qual e pela qual eu realmente vivo - executo ações". 
$\mathrm{O}$ ato reflexivo coloca o sujeito em articulação com o realizado, com o pensado, e ao mesmo tempo com os sentidos produzidos pela ação efetivada, com isso adquire-se a dimensão da complexidade, pois exige um envolvimento consciente do próprio ato. Diante disso, no ato reflexivo "[...] este ser não pode ser determinado na categoria da consciência teórica não participante - ele pode ser determinado apenas na categoria de comunhão real, isto é, de um ato realmente realizado, nas categorias da efetiva-participativa da experiência da unidade concreta e singular com o mundo" (BAKHTIN, 2010, p. 31).

\section{$\mathrm{O}$ ato de encantar-se com o fazer pedagógico}

Quando Manuel de Barros (2006) poeticamente nos declara que a importância das coisas não se mede com fita métrica, mas é o encantamento pela coisa ou por algo que lhe atribuirá a devida importância, o autor nos coloca diante de uma relação de enredamento entre a importância das coisas e o ato de encantar-se por elas. Primeiramente, podemos refletir, de forma mais genérica/abrangente, qual a importância ou o grau significativo do processo de formação na vida docente? O encantar-se por algo que fazemos está além de um simples gosto, visto que se amplia na compreensão da sedução, do cativar-se, do fascinar-se, do agradar extremamente, do ser tomado de intensa admiração por algo. O encantar-se por algo ocupa um patamar superior de importância a partir daquilo que me envolve e toca intimamente.

O encantamento nem sempre é perceptível, se ofusca mediante a inúmeras situações de descontentamento vivenciadas na nossa profissão. São entraves, como as decepções e frustrações consigo mesmo e com o outro, a impossibilidade de atingirmos as metas propostas e solucionarmos, a falta de resposta para as questões que nossa profissão nos apresenta.

Quando na penumbra das manhãs frias e encobertas pela névoa matinal, a renúncia ao aconchego do lar, tem-se na súplica poética de Adélia Prado (1993, p. 27), uma cumplicidade ao dizer "[...] quero uma licença de dormir,/ perdão pra descansar horas a fio/ em ao menos sonhar/ a leve 
palha de um pequeno sonho. / Quero o que antes da vida foi o sono profundo das espécies/ a graça de um estado/ semente./ Muito mais que raízes".

Sem o privilégio de assumir o estado "semente", perdidos na tranquilidade do nada a fazer e dormente em leito fértil, procura-se assumir a formação docente como um momento de dedicação de um tempo que é precioso, o que se torna uma postura de combate ao rotineiro, ao comodismo, ao cansaço, nem sempre movidos pelo encantamento ao estudo. Leva o professor a questionar o quanto o processo de formação pode lhe trazer vantagens, quando este lhe rouba algo importante em sua vida que é o tempo de descaço?

A atuação do professor é vista, muitas vezes, apenas na dimensão da formação do outro, na perspectiva daquele que ensina, responsável por apresentar e garantir a compreensão de um dado conteúdo. A ênfase à dimensão da formação de si mesmo, na perspectiva daquele que aprende, pouco se vê colocada em pauta.

A admiração ou sedução por aquilo que fazemos nos impele a orientação de nossas atitudes e a tomada de decisões em prol do benefício daquilo a que nos propusemos, deixamos pessoas queridas, abdicamos do prazer do descanso, nos submetemos a constantes desafios à superação dos nossos limites intelectuais, incorporando nas semanas de trabalho, ações de compromisso e dedicação, de reorganização das funções psicológicas superiores como atenção voluntária, memorização ativa, pensamento abstrato, análise reflexiva, o que requer estudo e leituras constantes, esforço no aprimoramento intelectual e uma linguagem escrita mais refinada.

\section{$\mathrm{O}$ ato da empatia}

De acordo com Bakhtin (2010), um momento considerado essencial da contemplação estética é a identificação com o sujeito, ou seja, a empatia, definida pelo autor como a capacidade de ver o outro dentro de sua própria essência. 
A empatia é percebida como um ato de complexidade na relação interpessoal, envolve um processo interdiscursivo, não demarcado apenas pela linguagem verbal. Para Bakhtin, esse momento de empatia é sempre seguido do momento de objetivação, isto é colocar-se do lado de fora da individualidade percebida pela empatia, um separar-se do objeto, um retorno a si mesmo.

O ato de empatia não se resume em colocar-se no lugar do outro, segundo Bakhtin (2010, p. 33) "[...] realiza alguma coisa que não existia nem no objeto de empatia, nem em mim mesmo, antes do ato da identificação, e através desta alguma coisa realizada o Ser-evento é enriquecido (ele não permanece igual a ele mesmo)".

Além do envolvimento de proximidade ao outro, na interatividade e interdiscursividade, não se refere a um ato que anula a personalidade, mas antes requer um profundo conhecimento de si mesmo, visto que a empatia, isto é, a capacidade de me colocar no lugar do outro, não me destitui do meu eu, não me faz perder meu próprio lugar ou a característica única enquanto pessoa, contudo pressupõe o reconhecimento de minha própria singularidade e de um posicionamento em relação ao outro. Assume-se, com isso, um ato de compreensibilidade e sensibilidade.

\section{Considerações finais}

Este trabalho, ao assumir como objetivo a discussão sobre o processo de formação docente, a partir da perspectiva interdiscursiva em aproximação com a Pedagogia Humanizadora, sinaliza a reflexibilidade da prática pedagógica como um ato dialógico.

Ao abrir um espaço para se compreender que o ato de pensar sobre o fazer pedagógico no cotidiano escolar, coloca o professor num movimento de rotação de docente atuante para a condição de discente operante, o que requer não apenas o domínio de um conhecimento ou de um conteúdo temático, mas o posicionamento reflexivo que promove ações e 
relações interpessoais, exigindo ultrapassar a si mesmo e se colocar rumo ao outro em busca da superação de limites e capacidades.

$\mathrm{O}$ ato dialógico não se constitui em uma atitude isolada, mas envolve atos, outros, como o ato de reflexibilidade, o ato de encantar-se com a própria prática e o ato de empatia. Define-se como a capacidade de aprendizagem e de (auto)regulação de ações e atuações. O processo de aprendizagem articula-se a partir da desaprendizagem, como dito por Caeiro, heterônimo de Pessoa (1995), primeiramente, no viés do discurso incorporado, desaprender pode ser entendido, a princípio, como o ato responsivo de se posicionar frente ao processo educativo, despir-se de saberes arraigados e desafiar-se a novos conhecimentos.

Demanda a atitude de pensar e repensar, de organizar e reorganizar ações a partir de si mesmo em características assumidas mediante às práticas repudiadas, próprias de discentes, quando se está em estado de formação docente, como a indiferença, o descompromisso, a ausência, a não pontualidade, entre outras. Em segundo, o ato de desaprender exige um ato responsivo de se refletir sobre concepções teóricas e práticas vivenciadas, o que sei soma-se ao que não sei, ou aquilo que acho que sei, para então produzir um novo saber.

A reflexão proposta redireciona-se à dialogicidade como ato ativador do processo de humanização, num constante ir e vir de um processo de construção, reconstrução ou desconstrução de um diálogo interior, permitindo que os sujeitos se formem e se constituam para, assim, contribuírem de modo significativo no processo de formação do outro. A relação dialógica exige do sujeito uma prática responsiva; acreditando, conforme Barthes (2004, p. 15), que "é a linguagem que ensina a definição de homem e não o contrário".

\section{Referências}

AMORIM, M. Para uma filosofia do ato: "válido e inserido no contexto". In: BRAIT, B. (Org.). Bakhtin, dialogismo e polifonia. São Paulo: Contexto, 2009. 
BAKHTIN, M. M. Marxismo e filosofia da linguagem. São Paulo: Hucitec, 2006.

BAKHTIN, M. M. Para uma filosofia do ato responsável. Trad. Valdemir Miotello e Carlos Arberto Faraco. São Carlos: Pedro \& João Editores, 2010.

BALZAN, N. C. Discutindo o processo de socialização profissional. In: REALI, A. M. de M. R.; MIZUKAMI, M. da G. N. (Orgs.). Formação de professores: tendências atuais. São Carlos: EDUFSCar, 1996. p. 47-91.

BARROS, M. Memórias Inventadas: A Segunda Infância. São Paulo: Planeta, 2006.

BARTHES, R. O rumor da língua. Trad. Mario Laranjeira. $2^{\mathrm{a}}$ ed. São Paulo: Martins Fontes, 2004, p. 462.

BRASIL. Ministério da Educação; Conselho Nacional de Educação; Câmara de Educação Básica; Resolução 4 de 13 de junho de 2010. Define Diretrizes Curriculares Nacionais para Educação Básica. Brasília: MEC/CNE/CEB, 2010.

BRASIL. Ministério da Educação; Plano Nacional de Educação 2014-2024. Lei no 13.005, de 25 de junho de 2014, que aprova o Plano Nacional de Educação (PNE) e dá outras providências. Brasília: Câmara dos Deputados; Edições Câmara, 2014. BRASIL. Ministério da Educação e Cultura. Base Nacional Comum Curricular. SEE: Brasília, 2015.

CANDAU, V. M. F. A formação continuada de professores: tendências atuais. In: REALI, A. de M. R.; MIZUKAMI, M. da G. N. (Orgs.). Formação de professores: tendências atuais: São Carlos: EDUFSCar, 1996. p. 139-152.

CONTRERAS, J. A autonomia de professores. São Paulo: Cortez, 2002.

FALSARELLA, A. M. Formação continuada e prática de sala de aula: os efeitos da formação continuada na atuação do professor. Campinas, São Paulo: Autores Associados, 2004.

FERREIRA, A. T. B.; ALBUQUERQUE, E. B. C. de; LEAL, T. F. (Orgs.). Formação continuada de professores. Belo Horizonte: Autêntica, 2007.

FREIRE, P. Pedagogia do Oprimido. 17. ed. Rio de Janeiro: Paz e Terra, 1987. 
FREIRE, P. Pedagogia da Autonomia: saberes necessários à prática educativa. São Paulo: Paz e Terra, 1996.

FREITAS, A. S. de. A questão da experiência na formação profissional dos professores. In: Ferreira, A. T. B.; Albuquerque, E. B. C. de; LEAL, T. F. (Orgs.). Formação continuada de professores. Belo Horizonte: Autêntica, 2007.

MIZUKAMI, M. G. N. Docência, trajetórias pessoais e desenvolvimento profissional. In: REALI, A. M. M. R.; MIZUKAMI, M. G. N. Formação de professores: tendências atuais. São Carlos: EDUFSCar, 1996. p. 59-89.

NÓVOA, A. Vida de professores. Lisboa: Porto Editora, 1989.

NÓVOA, A. (Org). Os professores e a sua formação. Lisboa: Instituto de Inovação Educacional, 1995.

PÉREZ FERRA, M. La actitude indagadora del professor: um proceso para desenrrollar competencias em los docentes. Revista Curricullum y formación del profesorado, v.17, n.13, p. 57-72, sept. /deciembro, 2013.

PERRENOUD, P. Dez novas competências para ensinar. Trad. Patrícia Chittoni Ramos. Porto Alegre: Artmed, 2000.

PERRENOUD, P.; THURLER, M. G. As competências para ensinar no século XXI: a formação dos professores e o desafio da avaliação. Porto Alegre: Artmed, 2002.

PESSOA, F. Poesia Completa de Alberto Caeiro. São Paulo: Companhia das Letras, 2005.

PRADO, A. Bagagem. São Paulo: Editora Siciliano, 1993.

PRADO, J. C.; TESCAROLO, R. A pedagogia encharcada de amor de Paulo Freire na prática docente. In: Anais do..., EDUCERE: saberes docentes. Curitiba: Champagnat, 2007.

SOBRAL, A. O ato "responsível", ou ato ético em Bakhtin, e a centralidade. SIGNUM: Estudos da Linguagem, Londrina, n. 11/1, p. 219-235, jul. 2008. 
SOUSA NETO, M. F. de. O ofício, a oficina e a profissão: reflexões sobre o lugar social do professor. Caderno Cedes, Campinas, vol. 25, n. 66, p. 249-259, maio/ ago. 2005.

TARDIF, M. Saberes docentes e formação inicial. Petrópolis: Vozes, 2002.

Recebido: 25/04/2016

Received: 04/25/2016

Aprovado: 30/06/2016

Approved: 06/30/2016 